PNNL-13044

\title{
Long-Range Neutron Detection
}

\author{
A.J. Peurrung \\ D.C. Stromswold \\ R.R. Hansen \\ P.L. Reeder \\ D.S. Barnett
}

November 1999

Prepared for the U.S. D epartment of Energy under Contract D E-AC06-76RLO 1830 


\title{
DISCLAIMER
}

This report was prepared as an account of work sponsored by an agency of the United States Government. Neither the United States Government nor any agency thereof, nor Battelle Memorial Institute, nor any of their employees, makes any warranty, expressed or implied, or assumes any legal liability or responsibility for the accuracy, completeness, or usefulness of any information, apparatus, product, or process disclosed, or represents that its use would not infringe privately owned rights. Reference herein to any specific commercial product, process, or service by trade name, trademark, manufacturer, or otherwise does not necessarily constitute or imply its endorsement, recommendation, or favoring by the United States Government or any agency thereof, or Battelle Memorial Institute. The views and opinions of authors expressed herein do not necessarily state or reflect those of the United States Government or any agency thereof.

\author{
PACIFIC NORTHWEST NATIONAL LABORATORY \\ operated by \\ BATTELLE MEMORI AL INSTITUTE \\ for the \\ UNITED STATES DEPARTMENT OF ENERGY \\ under Contract DE-AC06-76RLO 1830
}

Printed in the United States of America

Available to DOE and DOE contractors from the

Office of Scientific and Technical Information, P.O. Box 62, Oak Ridge, TN 37831; prices available from $(615) 576-8401$.

Available to the public from the National Technical Information Service, U.S. Department of Commerce, 5285 Port Royal Rd., Springfield, VA 22161 
PNNL-13044

\title{
Long-Range N eutron Detection
}

\author{
A.J. Peurrung \\ D.C. Stromswold \\ R.R. Hansen \\ P.L. Reeder \\ D.S. Barnett
}

November 1999

Prepared for the U.S. D epartment of Energy under Contract D E-AC06-76RLO 1830

Pacific Northwest National Laboratory

Richland, Washington 99352 


\section{Summary}

A neutron detector designed for detecting neutron sources at distances of 50 to $100 \mathrm{~m}$ has been constructed and tested. This detector has a large surface area $\left(1 \mathrm{~m}^{2}\right)$ to enhance detection efficiency, and it contains a collimator and shielding to achieve direction sensitivity and reduce background. An unusual feature of the detector is that it contains no added moderator, such as polyethylene, to moderate fast neutrons before they reach the ${ }^{3} \mathrm{He}$ detector. As a result, the detector is sensitive mainly to thermal neutrons. The moderator-free design reduces the weight of the detector, making it more portable, and it also aids in achieving directional sensitivity and background reduction.

Test results show that moderated fission-neutron sources of strength about $3 \times 10^{5} \mathrm{n} / \mathrm{s}$ can be detected at a distance out to $70 \mathrm{~m}$ in a counting time of $1000 \mathrm{~s}$. The best angular resolution of the detector is obtained at distances of $30 \mathrm{~m}$ or less. As the separation distance between the source and detector increases, the contribution of scattered neutrons to the measured signal increases with a resultant decrease in the ability to detect the direction to a distant source.

Applications for which the long-range detector appears to be suitable include detecting remote neutron sources (including sources in moving vehicles) and monitoring neutron storage vaults for the intrusion of humans and the effects they make on the detected neutron signal. Also, the detector can be used to measure waste for the presence of transuranic material in the presence of high gamma-ray background. A test with a neutron source $\left(3 \times 10^{5} \mathrm{n} / \mathrm{s}\right)$ in a vehicle showed that the detector could readily measure an increase in count rate at a distance of $10 \mathrm{~m}$ for vehicle speeds up to $35 \mathrm{mph}$ (the highest speed tested). These results indicate that the source should be detectable at this distance at speeds up to $55 \mathrm{mph}$. 


\section{Contents}

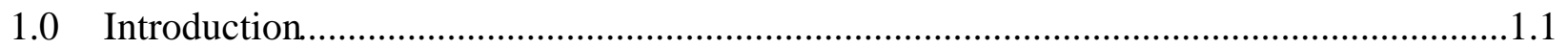

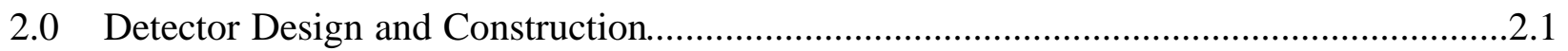

3.0 Tests to Characterize the Detector's Response..............................................................

4.0 Field Tests for Potential Applications ............................................................................ 4.1

4.1 Detection of Moving Source ................................................................................. 4.1

4.2 Neutron Source Storage Vault Monitoring ......................................................... 4.3

4.3 Transuranic Content of Radioactive Waste............................................................ 4.5

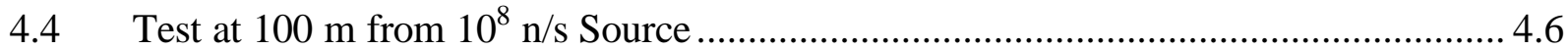

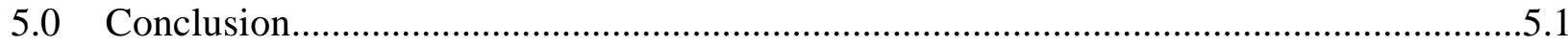

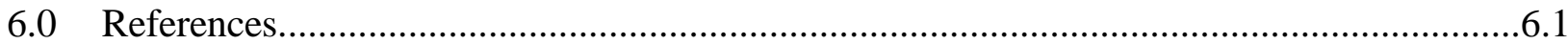




\section{Figures}

Figure 2.1. Long-Range Neutron Detector with Collimator, Mounted on Cart for Field Tests ..2.1

Figure 2.2. Comparison of Detection Probability in a ${ }^{3} \mathrm{He}$ Detector for Neutrons Passing

Through $1 \mathrm{~kg} / \mathrm{m}^{2}$ Shielding Material of ${ }^{10} \mathrm{~B}, \mathrm{Cd}$, or $\mathrm{Gd}$.

Figure 2.3. Honeycomb Collimator Covered with ${ }^{10} \mathrm{~B}$ to Absorb Thermal Neutrons and Provide

Angular Sensitivity for the ${ }^{3} \mathrm{He}$ Detector Located Behind the Collimator.

Figure 3.1. Background-Subtracted Response of Detector to ${ }^{252} \mathrm{Cf}$ Source Enclosed by

Polyethylene (5-cm thick) at Various Source-to-Detector Distances.

Figure 3.2. Normalized Angular Response of Detector to a ${ }^{252} \mathrm{Cf}$ Source Enclosed by Polyethylene (5-cm thick) at $3 \mathrm{~m}$ and $30 \mathrm{~m}$.

Figure 3.3. Normalized Angular Response of Detector to a Bare (no polyethylene) ${ }^{252} \mathrm{Cf}$ Source at $3 \mathrm{~m}$ and $30 \mathrm{~m}$.

Figure 3.4. Background-Subtracted Count Rate at $30 \mathrm{~m}$ for Bare Detector (Collimator and Rear Shield Removed); also Background-Subtracted Count Rate from Collimated Detector..3.4

Figure 3.5. Count Rate at $30 \mathrm{~m}$ for Various Detector and ${ }^{252} \mathrm{Cf}$ Source Conditions.

Figure 3.6. Number of Standard Deviations for Counts Obtained in 1000-s Runs at $30 \mathrm{~m}$ for

Various Detector and ${ }^{252} \mathrm{Cf}$ Source Conditions.

Figure 3.7. Ratio of Counts Obtained in $2.54 \times 35.6 \mathrm{~cm}{ }^{3} \mathrm{He}$ Detector when it is Covered by a

Cadmium Sleeve, Compared to Counts for the Bare Detector.

Figure 3.8. Background-Subtracted Count Rates Obtained with Long-Range Detector for

Various Source and Detector Configurations (same configurations as in Figure 3.7)......3.7

Figure 4.1. Long-Range Detector Used to Detect Neutrons Emitted from a Source in a Truck .4.2

Figure 4.2. Count Rates Obtained as Truck Containing Moderated ${ }^{252}$ Cf Source Drives Past

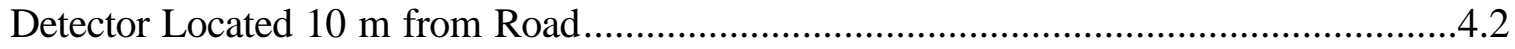

Figure 4.3. Long-Range Detector in Vault Where Radioactive Sources are Stored...................4.3

Figure 4.4. Changes in Observed Count Rate when Various Numbers of People are Located

Between the Neutron Sources in a Storage Vault and the Detector................................4.4

Figure 4.5. Count Rates Observed by Detector Looking into Storage Vault and then Rotated $90^{\circ}$ to Simulate Movement of the Detector if it Were Mounted on a Door that Swings

Through $90^{\circ}$

Figure 4.6. Graphite "Cave" (foreground) Used to Moderate Neutrons and Reflect them Toward the Detector Located Several Meters Away.....

Figure 4.7. Count Rate Obtained at a Distance of $100 \mathrm{~m}$ from a $10^{8} \mathrm{n} / \mathrm{s}$ Source Being Moved Inside a Building .4 .6 


\subsection{Introduction}

The ability to detect neutron sources at long range (50 to $100 \mathrm{~m})$ has clear applications for national security. Plutonium and other neutron-emitting sources produce penetrating radiation that can be difficult to conceal by shielding. A neutron detector mounted in a vehicle can be useful for search and interdiction as a complement to gamma-ray detectors.

Several approaches to achieving long-range neutron detection are possible, and these have been discussed in detail previously (Peurrung et al. 1997 and 1998). These approaches include using moderated detectors, self-coded arrays employing either thermal or fast neutrons (Vanier et al. 1995), and moderator-free detectors that are either directional or omnidirectional. Moderated detectors produce the greatest count rate, but they can be heavy and have little directional sensitivity. Self-coded arrays have good directional sensitivity (indeed, source imaging capability), but their efficiency is low. Moderator-free detectors have good sensitivity to the thermal portion of a neutron spectrum (which may constitute about $10 \%$ of the total spectrum), and they can be made to be directional through shielding and collimators.

Most neutron detectors contain hydrogenous material to moderate the energy of neutrons down to thermal energy where they can be readily detected through interactions with ${ }^{3} \mathrm{He},{ }^{10} \mathrm{~B}$, or other capture agents. The moderator produces a detection system with enhanced sensitivity to the energetic portion of the incident neutron spectrum. Disadvantages of a moderated detector, however, are the increased weight of the detector system resulting from the moderating material, the difficulty of achieving directional sensitivity to the incident neutrons, and increased background counts.

Both thermal and non-thermal neutrons can travel long distances through air, making remote detection possible. The incident neutron spectrum depends both on the original (source) spectrum and on the moderation that occurs through neutron interaction with air, soil, and building materials. Increased scattering of the neutrons tends to increase the thermal portion of the spectrum while reducing directional information. Previous reports (Peurrung et al. 1998) ${ }^{1}$ contain results of computer simulations to determine the effect of air and ground scatter on the performance of a thermal neutron detector. In brief, although our detector does not have a moderator, the environment through which the neutrons pass to reach the detector does moderate the fast neutrons and significantly affects the energy spectrum incident on the detector.

Staff at Pacific Northwest National Laboratory ${ }^{2}$ have explored the concept of using a moderator-free neutron detector for long-range and directional measurements. To test the feasibility of such a detector, an array of ${ }^{3} \mathrm{He}$ tubes has been assembled to produce a detector with a surface area of $1 \mathrm{~m}^{2}$. This detector has a collimator on its front and shielding material on the back and sides to reduce the background counts and enhance directional sensitivity.

\footnotetext{
${ }^{1}$ AJ Peurrung, RR Hansen, PL Reeder, and DC Stromswold. "Moderator-Free Neutron Detection," presented at IEEE Nuclear Science Symposium (1998).

${ }^{2}$ Pacific Northwest National Laboratory is operated for the U.S. Department of Energy by Battelle under Contract DE-AC06-76RLO 1830.
} 
We evaluated this detector's performance with a series of tests to determine its response to distant neutron sources and the angular sensitivity achieved by the collimator and shielding. Additional tests have explored applications such as detecting a neutron source passing by the detector in a vehicle and using the detector to monitor human intrusion into the neutron radiation of a storage vault. The results of these tests are provided in later sections of this report. 


\subsection{Detector Design and Construction}

Figure 2.1 shows the long-range neutron detector with its ${ }^{3} \mathrm{He}$ tubes for neutron detection and a collimator on the front for angular sensitivity. The ${ }^{3} \mathrm{He}$ tubes are located side-by-side to produce a surface area of $1 \mathrm{~m}^{2}$. Each of the 23 tubes has a diameter of $5 \mathrm{~cm}$, a length of $86 \mathrm{~cm}$, and a gas pressure of 4 atmospheres. As shown in Figure 2.1, the detector array is mounted on a small cart for movement during the outdoor tests.

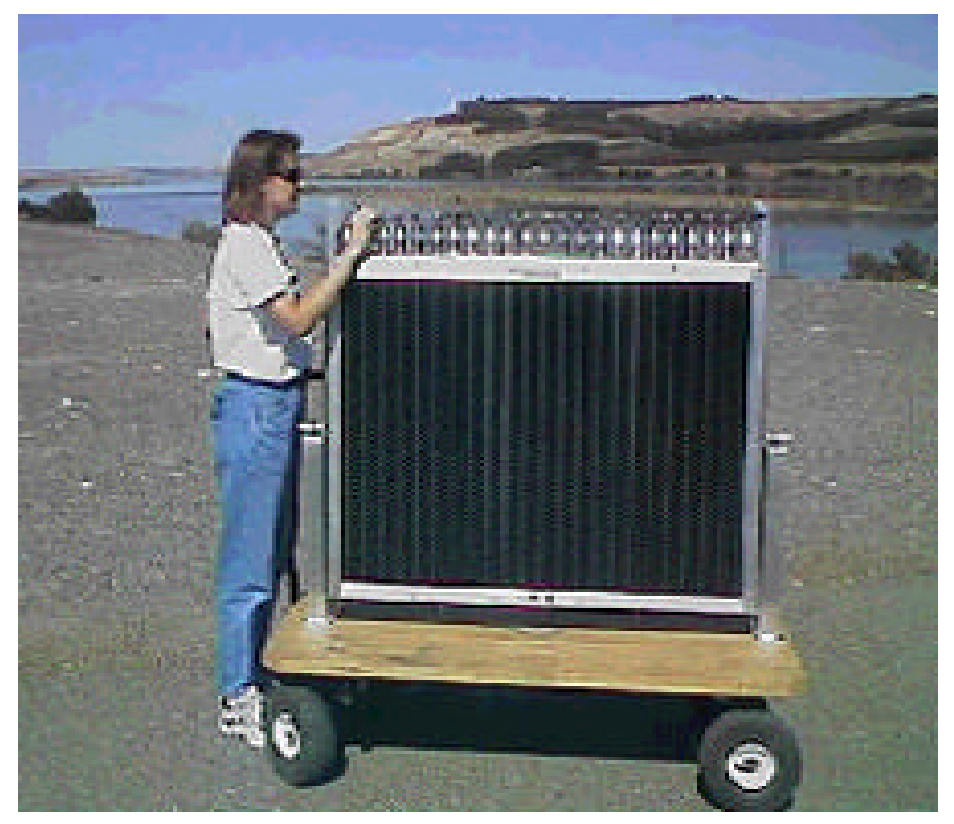

Figure 2.1. Long-Range Neutron Detector with Collimator, Mounted on Cart for Field Tests

Signals from each ${ }^{3} \mathrm{He}$ tube are processed individually by an amplifier and discriminator (Precision Data Technology, Inc., Model 110A), and the combined neutron counts from all tubes are stored in a computer. The power used by the detector is about 6 watts, not including the laptop computer. During some of the tests to characterize the detector's response, we used alternative electronics (Ortec 142PC preamplifiers and Ortec 572 amplifiers) to monitor spectrum shapes and possible temperature-related gain shifts with a multichannel analyzer.

The collimator (manufactured by EuroCollimators, Ltd of Cheltenham, England) on the front of the detector is an aluminum hexagonal (honeycomb) grid coated with ${ }^{10} \mathrm{~B}$ to absorb thermal neutrons. The boron is sprayed onto the aluminum as a mixture of boron carbide powder $\left(\mathrm{B}_{4} \mathrm{C}\right)$ and binder material. The boron is enriched to about $90 \%{ }^{10} \mathrm{~B}$, and it has a ${ }^{10} \mathrm{~B}$ density of $1 \mathrm{~kg} / \mathrm{m}^{2}$ as applied to the collimator. This same density of ${ }^{10} \mathrm{~B}$ is present on the aluminum plates that enclose the back and sides of the detector. The organic binder used to adhere the $\mathrm{B}_{4} \mathrm{C}$ to the collimator and aluminum plates produces some undesired moderation of energetic neutrons, but calculations show that it increases the background by less than $25 \%$. 
Boron is used rather than cadmium or gadolinium because of its superior ability to attenuate epithermal neutrons. Figure 2.2 compares the calculated detection probability for neutrons passing through ${ }^{10} \mathrm{~B}, \mathrm{Cd}$, and $\mathrm{Gd}$ absorbers $1 \mathrm{~kg} / \mathrm{m}^{2}$ thick. After passing through the absorber material, neutrons interact in ${ }^{3} \mathrm{He}$ gas $5 \mathrm{~cm}$ thick with a pressure of 4 atmospheres. As shown in the figure, ${ }^{10} \mathrm{~B}$ is superior for attenuating neutrons over the energy range of 0.01 to $100 \mathrm{eV}$. Although boron is more difficult to apply as a shielding material than is either cadmium or gadolinium, its superior attenuation of low-energy neutrons makes it advantageous for our neutron detector. The low background that results from ${ }^{10} \mathrm{~B}$ shielding both aids the signal-tobackground ratio and helps to achieve good angular sensitivity from the collimated detector.

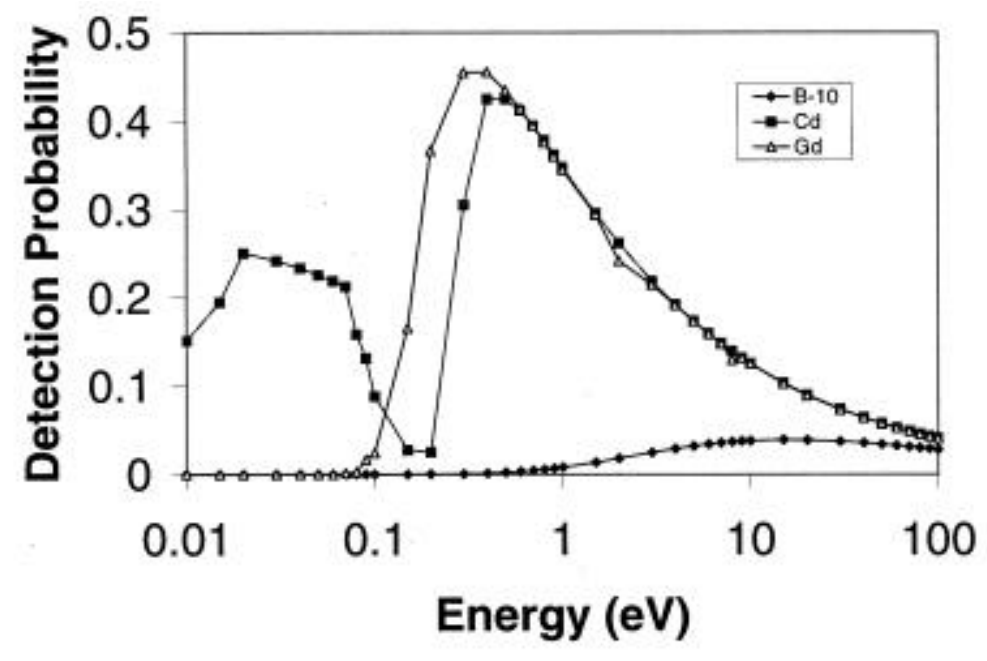

Figure 2.2. Comparison of Detection Probability in a ${ }^{3} \mathrm{He}$ Detector for Neutrons Passing Through $1 \mathrm{~kg} / \mathrm{m}^{2}$ Shielding Material of ${ }^{10} \mathrm{~B}, \mathrm{Cd}$, or $\mathrm{Gd}$. The best shielding is provided by ${ }^{10} \mathrm{~B}$.

Figure 2.3 shows a close-up photograph of the honeycomb collimator. The hexagonal cells of the collimator have a face-to-face separation distance of $1.9 \mathrm{~cm}$ and depth of $2.5 \mathrm{~cm}$. The acceptance angle of the collimator is approximately $45^{\circ}$. This corresponds to an opening of $5 \%$ of the total solid angle $(4 \pi)$. This relatively large angle is advantageous for long-range measurements where thermal neutrons are likely to have scattered before reaching the detector. The scattered neutrons produce a "cloud" of neutrons in the direction of the source, and the large acceptance angle allows the off-axis neutrons to be detected. 


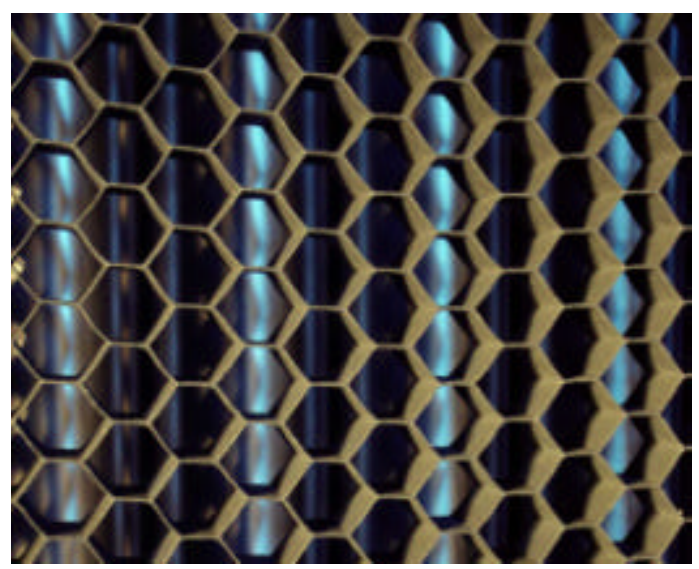

Figure 2.3. Honeycomb Collimator Covered with ${ }^{10} \mathrm{~B}$ to Absorb Thermal Neutrons and Provide Angular Sensitivity for the ${ }^{3} \mathrm{He}$ Detector Located Behind the Collimator 


\subsection{Tests to Characterize the Detector's Response}

The long-range neutron detector was tested outdoors to minimize environmental perturbations, such as scattering of neutrons from laboratory furniture and room walls. The tests measured the response of the detector at various distances from a source, angular response due to the collimator, and effects related to the neutron source energy. $\mathrm{A}{ }^{252} \mathrm{Cf}$ source $\left(3.36 \times 10^{5} \mathrm{n} / \mathrm{s}\right)$ was used to produce a broad spectrum of energies having a median energy of about $2 \mathrm{MeV}$. Placing the source in a polyethylene box moderated the energy of the neutrons, giving an enhanced thermal-neutron flux. In some tests, the source was covered with cadmium to reduce the number of thermal neutrons (some of which arise from moderation in the source holder).

Figure 3.1 shows the results of tests of the detector at various distances from the ${ }^{252} \mathrm{Cf}$ source. For these tests, the source was enclosed by a box of polyethylene (5-cm-thick walls) and located at a distance of about $1 \mathrm{~m}$ above the ground. The detector was moved away from the source until the signal approached background value, which in this case occurred at about $70 \mathrm{~m}$. Experience showed that care must be taken in selecting experimental sites to obtain a location where the natural background is not increased by radiation from nearby buildings. At Hanford's 300 Area, where all tests of the detector occur, the background can vary considerably, depending on the proximity to specific buildings where sources are stored. The lowest background obtained with the detector during the tests was $1.3 \mathrm{c} / \mathrm{s}$.

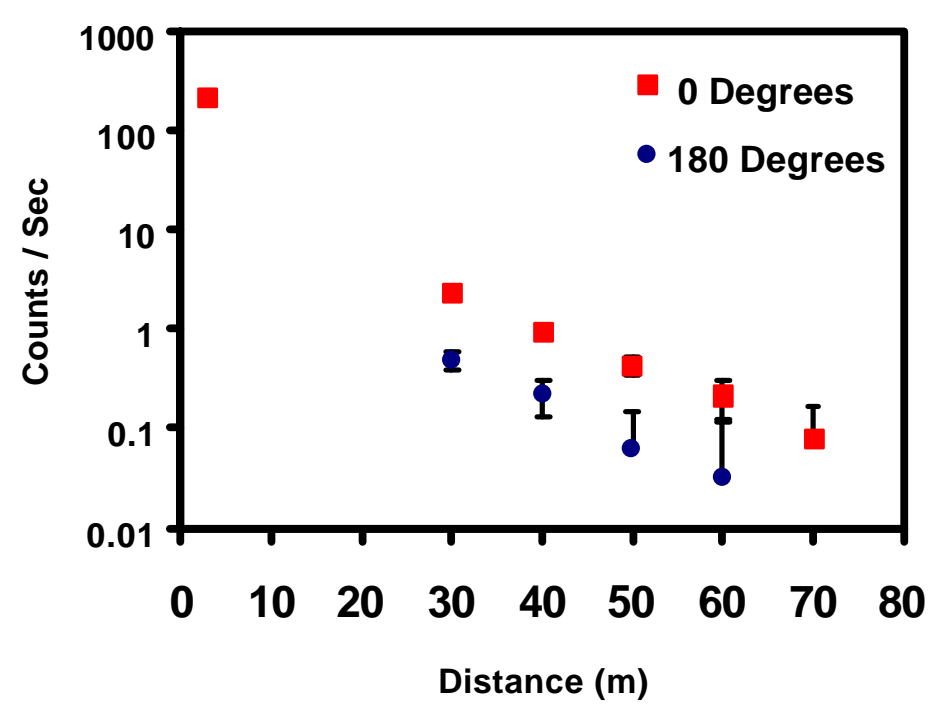

Figure 3.1. Background-Subtracted Response of Detector to ${ }^{252} \mathrm{Cf}$ Source Enclosed by Polyethylene (5-cm thick) at Various Source-toDetector Distances. Square points are for the detector aimed toward the source $\left(0^{\circ}\right)$, and filled circles are for the detector aimed away from the source $\left(180^{\circ}\right)$. 
As shown in Figure 3.1, the background-subtracted count rate is about $200 \mathrm{c} / \mathrm{s}$ when the detector is $3 \mathrm{~m}$ away from the polyethylene-enclosed source. At $30 \mathrm{~m}$, the count rate is about $2 \mathrm{c} / \mathrm{s}$, and at $70 \mathrm{~m}$, it is about $0.1 \mathrm{c} / \mathrm{s}$. Data for distances between 3 and $30 \mathrm{~m}$ were not measured because the goal of the experiments was to determine the longest distance at which the source can be detected in measurement times of $1000 \mathrm{~s}$.

Also shown on Figure 3.1 are the background-subtracted count rates obtained at various distances when the detector was aimed $180^{\circ}$ away from the source rather than toward the source. These count rates are typically about 8 times lower than those for the detector aimed toward the source. The count rates for the $180^{\circ}$ runs were not at background levels primarily because the scatter of neutrons from the air and ground created thermal neutrons traveling in various directions. Thus, even when the detector was aimed away from the source, neutrons that scattered in the environment still entered the detector through the collimator.

Figure 3.2 shows the normalized angular response of the detector to a ${ }^{252} \mathrm{Cf}$ source located inside a polyethylene box at a distance of $1 \mathrm{~m}$ above the ground. The detector was positioned at two different distances $(3 \mathrm{~m}$ and $30 \mathrm{~m}$ ) from the source. At each location, the detector was rotated about a vertical axis to various angles with respect to the direction to the source $\left(0^{\circ}\right.$ is toward the source). At each angle, counts were collected for $1000 \mathrm{~s}$. As expected, the count rate was at its maximum when the detector was aimed at the source, and the count rate decreased with increasing rotation angle. This decrease in counts resulted from the collimator on the front of the detector and the smaller surface area exposed to the source as the result of

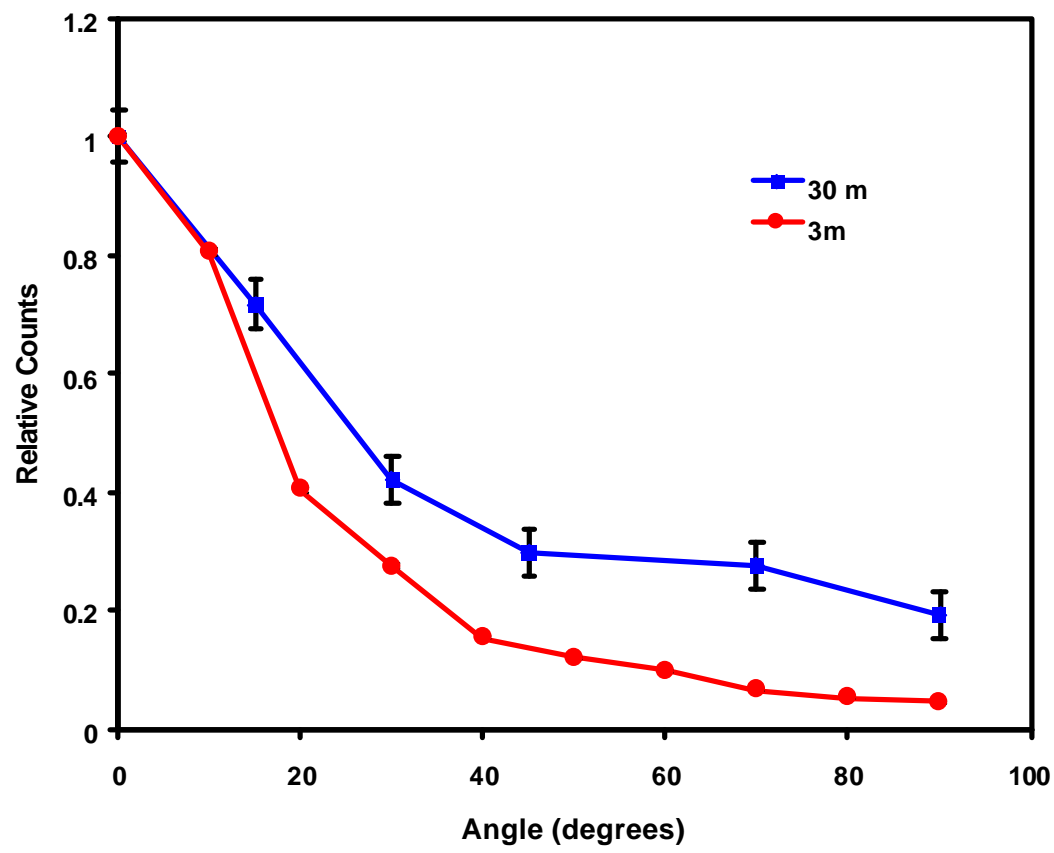

Figure 3.2. Normalized Angular Response of Detector to a ${ }^{252} \mathrm{Cf}$ Source Enclosed by Polyethylene (5-cm thick) at $3 \mathrm{~m}$ and $30 \mathrm{~m}$ 
rotation. The data collected at a 3-m separation from the source had a narrower angular response function than did the 30-m data. This is reasonable because at the longer separation distance, the neutrons had more chance to scatter and reach the detector at broader incidence angles.

Figure 3.3 shows the normalized angular response of the detector to a bare ${ }^{252} \mathrm{Cf}$ source (i.e., no added polyethylene around the source). When the detector was $30 \mathrm{~m}$ from the source, no statistically significant difference in count rate was detected within the 1000-s counting period as the detector was rotated to various angles. This suggests that the majority of the signal from this source at $30 \mathrm{~m}$ resulted from fast neutrons that thermalized in the air or ground near the detector, rather than from the small fraction of the emitted neutron spectrum that is thermal. Also shown in Figure 3.3 is the angular response when the detector was $3 \mathrm{~m}$ from the bare source. At this distance, the angular response was broad, indicating that the main signal was coming from fast neutrons that moderated in the air or ground in the vicinity of the source and detector.

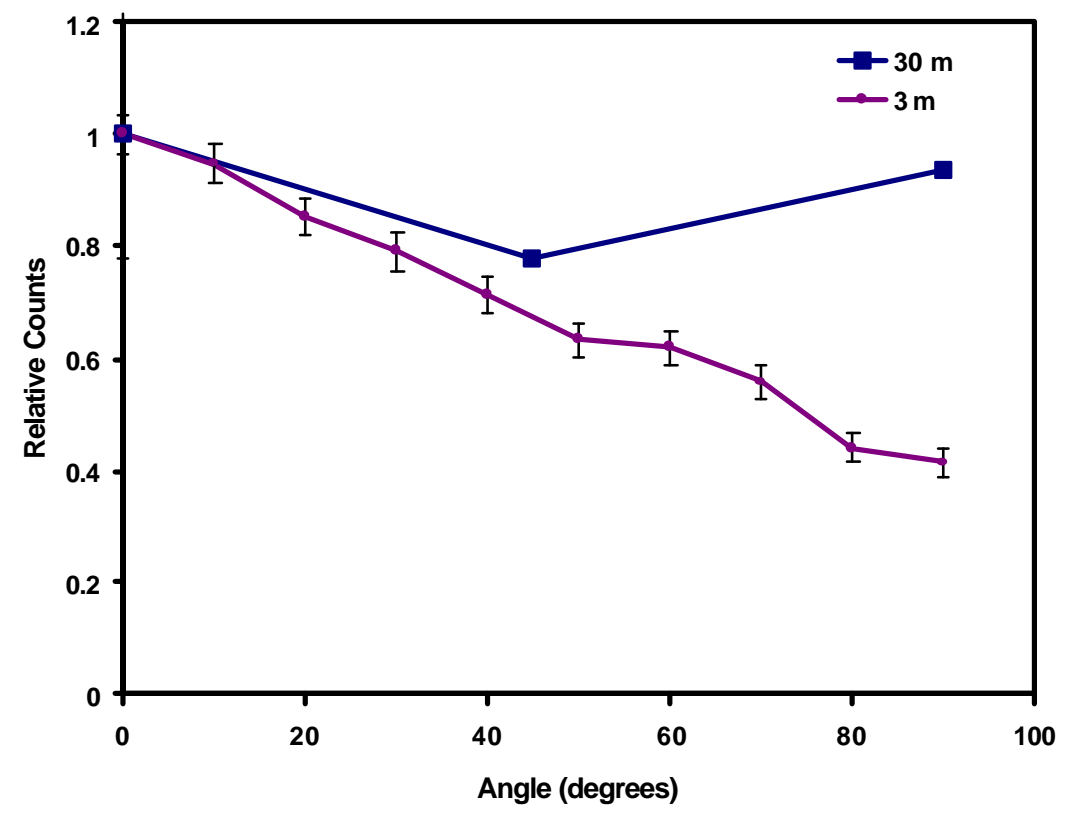

Figure 3.3. Normalized Angular Response of Detector to a Bare (no polyethylene) ${ }^{252} \mathrm{Cf}$ Source at $3 \mathrm{~m}$ and $30 \mathrm{~m}$

To specifically test the effects of the ${ }^{10} \mathrm{~B}$ shielding on the detector, the collimator on the front of the detector and the back shield were removed for some tests to produce a "bare" detector. The ${ }^{10} \mathrm{~B}$ on the sides remained in place for these tests, but the side areas were small relative to the front and back of the detector. Removing the collimator and back shield increased the background count rate in the detector from the normal $1.3 \mathrm{c} / \mathrm{s}$ to $11.3 \mathrm{c} / \mathrm{s}$. Figure 3.4 shows data collected at $30 \mathrm{~m}$ from the source with the collimated detector and the bare detector. With the bare detector, the background-subtracted count rate increased from 2.3 to $5.4 \mathrm{c} / \mathrm{s}$ for the moderated ${ }^{252} \mathrm{Cf}$ source. This increase of $3.1 \mathrm{c} / \mathrm{s}$ in the signal is significantly less than the increase in background $(10 \mathrm{c} / \mathrm{s})$ when the shield is removed, and this illustrates the importance of the ${ }^{10} \mathrm{~B}$ shielding in obtaining good signal-to-background ratios. The increase in the background- 
subtracted count rate resulted from adding neutrons that scattered in transit from the source to the detector and were incident on the detector at angles that would have been rejected if the shielding had been present. For the unmoderated ${ }^{252} \mathrm{Cf}$ source, the count rate increased from 0.4 to $1.2 \mathrm{c} / \mathrm{s}$ when the collimator and back shield were removed. The count rates obtained from the unmoderated source were low because the detector was insensitive to fast neutrons coming directly from the source. Scattering and moderation of fast neutrons through interactions with the ground and air were the principal sources of the thermal neutrons that were detected.

Figure 3.4 also shows data obtained when the detector was rotated $90^{\circ}$ away from the source. This gives a comparison of the angular response for the collimated and bare configurations of the detector. Because of changing the solid angle, some directional sensitivity remained for the detector even after removing the collimator and back shield, as shown in the decreased count rates at $90^{\circ}$ with the ${ }^{10} \mathrm{~B}$ shields removed. The angular sensitivity was less, however, than it was when the ${ }^{10} \mathrm{~B}$ shields were present. Specifically, the ratio of counts at $0^{\circ}$ and $90^{\circ}$ for the moderated source was about four times greater when the ${ }^{10} \mathrm{~B}$ shielding was present than when it was absent. This illustrates the importance of the shielding and collimator for achieving good angular sensitivity. When the source was bare, the background-subtracted count rates were very small, and no statistical difference was apparent for $0^{\circ}$ and $90^{\circ}$ between the bare and the collimated detector.

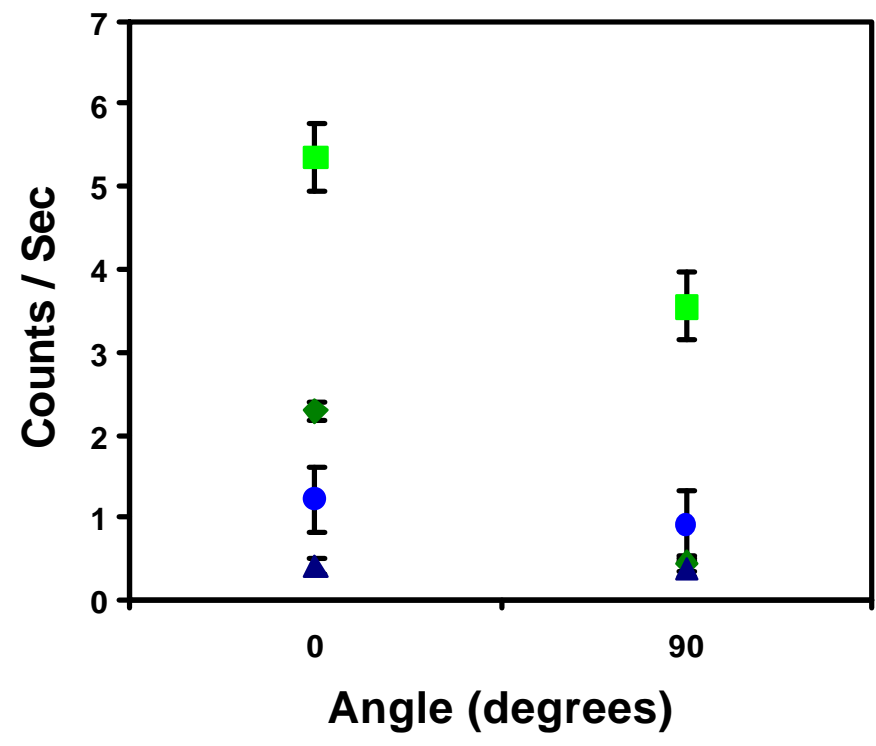

Moderated Source; Bare

Detector

$\checkmark$ Moderated Source;

Collimated Detector

- Unmoderated Source; Bare Detector

$\Delta$ Unmoderated Source; Collimated Detector

Figure 3.4. Background-Subtracted Count Rate at $30 \mathrm{~m}$ for Bare Detector (Collimator and Rear Shield Removed); also Background-Subtracted Count Rate from Collimated Detector 
For some tests, polyethylene was added around the detector to convert it to a more conventional, moderated detector. Sheets of polyethylene (thickness $3.8 \mathrm{~cm}$ ) were added to the front and back of the bare detector. Figure 3.5 shows the count rates obtained for three configurations of the detector: collimated (collimator and back shield of ${ }^{10} \mathrm{~B}$ present), bare (no collimator or back shield), and "poly" (no collimator or back shield, but with 3.8-cm-thick polyethylene sheets on front and back of detector). The data are presented for measurements at $30 \mathrm{~m}$ from the source, which is either enclosed in polyethylene or bare. The polyethylene increases the count rate over what it is with either the collimated (normal) configuration or the bare configuration. However, the absence of the collimator and the presence of the polyethylene also increase the background count rate from $1.3 \mathrm{c} / \mathrm{s}$ to $15.0 \mathrm{c} / \mathrm{s}$. (The purpose of the collimator and ${ }^{10} \mathrm{~B}$ shielding is to decrease the background so that small signals from neutrons accepted through the collimator can be detected.) An alternative way of presenting the data for the various configurations of the detector is to calculate the standard deviation of the signal and divide this into the observed (background-subtracted) counts to get the number of standard deviations of the signal above background. This is shown in Figure 3.6 for experimental collection times of $1000 \mathrm{~s}$. The normal configuration of the detector (collimator and back shield present) produced the largest number of standard deviations above background when the source was surrounded by polyethylene (i.e., a moderated source). For an unmoderated source, adding polyethylene to the detector enhanced the performance over that obtained with the normal configuration of the detector (which is designed to detect thermal neutrons). The moderator effectively randomizes the direction of the neutrons during the slowing-down process in the moderator, and no directionality beyond that of the solid angle exposed to the source is expected for the configuration with the moderator at the detector's location.

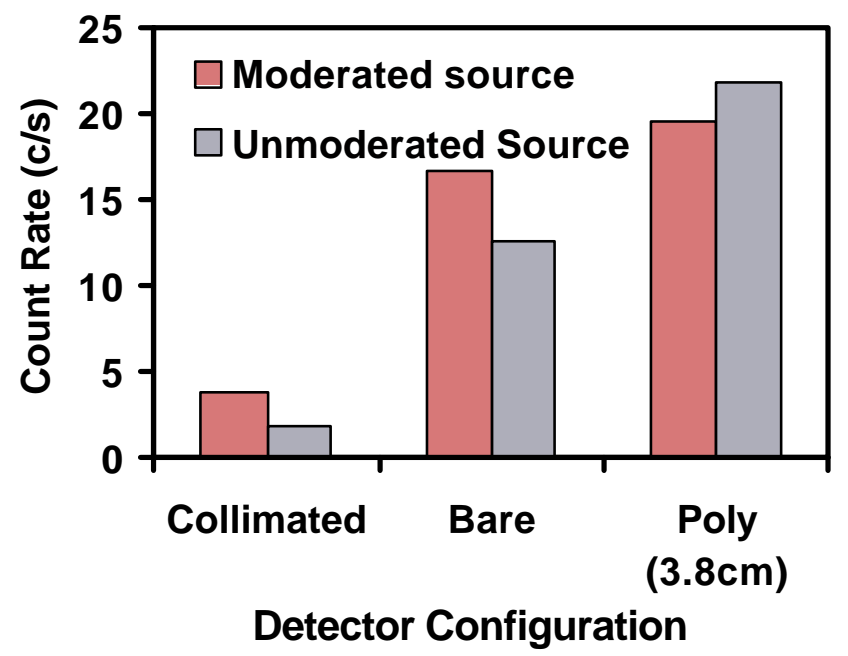

Figure 3.5. Count Rate at $30 \mathrm{~m}$ for Various Detector and ${ }^{252} \mathrm{Cf}$ Source Conditions 


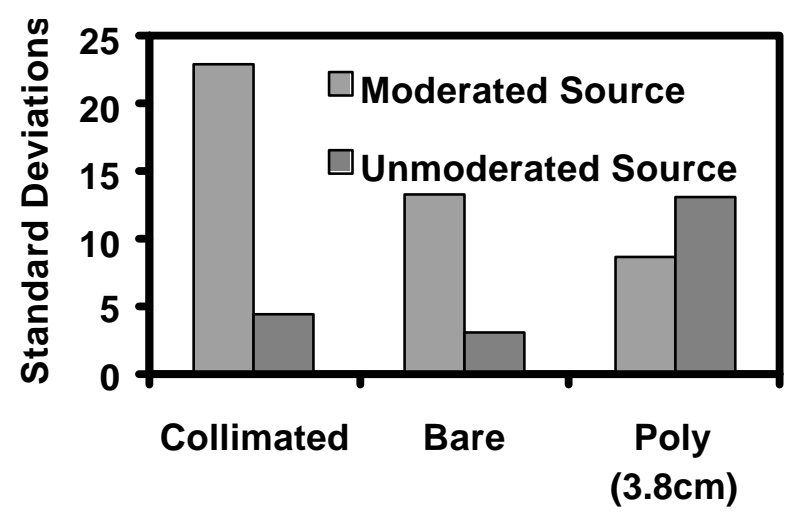

Detector Configuration

Figure 3.6. Number of Standard Deviations for Counts Obtained in 1000-s Runs at $30 \mathrm{~m}$ for Various Detector and ${ }^{252} \mathrm{Cf}$ Source Conditions

The response of the detector to a given source depends on the energy spectrum emitted by the source as well as the moderation of the neutrons as they travel from the source to the detector. To help in characterizing the energy of the neutrons from the ${ }^{252} \mathrm{Cf}$ source, data were collected using a single ${ }^{3} \mathrm{He}$ tube $(2.54 \mathrm{~cm}$ diameter, $35.6 \mathrm{~cm}$ length, 4 atmospheres $)$ at various distances from the source with the detector bare and also cadmium covered. The ratio of cadmium-to-bare counts gives the epithermal fraction of the neutron spectrum at the location of the detector. Figure 3.7 shows this ratio for several ${ }^{252} \mathrm{Cf}$ source configurations and two distances ( $3 \mathrm{~m}$ and $30 \mathrm{~m}$ ). The source configurations were as follows: (1) bare source, (2) source covered with cadmium (to eliminate thermal neutrons), (3) source surrounded by graphite moderator (thickness $20 \mathrm{~cm}$ ), and (4) source surrounded by polyethylene moderator (thickness $5 \mathrm{~cm}$ ). As shown in the figure, the epithermal fraction was greater at $30 \mathrm{~m}$ than it was at $3 \mathrm{~m}$ for all source configurations. This demonstrates that additional moderation of the neutron energy occurred during the longer flight paths to the more distant detector. The smallest difference in the ratio at the two distances occurred when the source was surrounded by polyethylene. The polyethylene clearly did the best job of moderating the source neutrons, and the added moderation in traveling from $3 \mathrm{~m}$ to $30 \mathrm{~m}$ was minimal.

Figure 3.8 shows the count rates obtained using the long-range detector for the four source configurations used in Figure 3.7 (bare ${ }^{252} \mathrm{Cf}$ source, source surrounded by cadmium, source surrounded by graphite, and source surrounded by polyethylene). The figure illustrates clearly that polyethylene around the source produced the highest detected count rate. Cadmium around the source had very little effect on the count rate, as expected from a source that should mainly produce fast neutrons. The count rates in Figure 3.8 for the $3-\mathrm{m}$ distance measurements were scaled by solid-angle calculations (a factor of 100) to give equivalent rates for plotting on the same scale as the 30-m data. The scaled values for the 3-m data do not coincide with the 30-m data because of additional moderation of the neutrons during the $30-\mathrm{m}$ travel distance. 


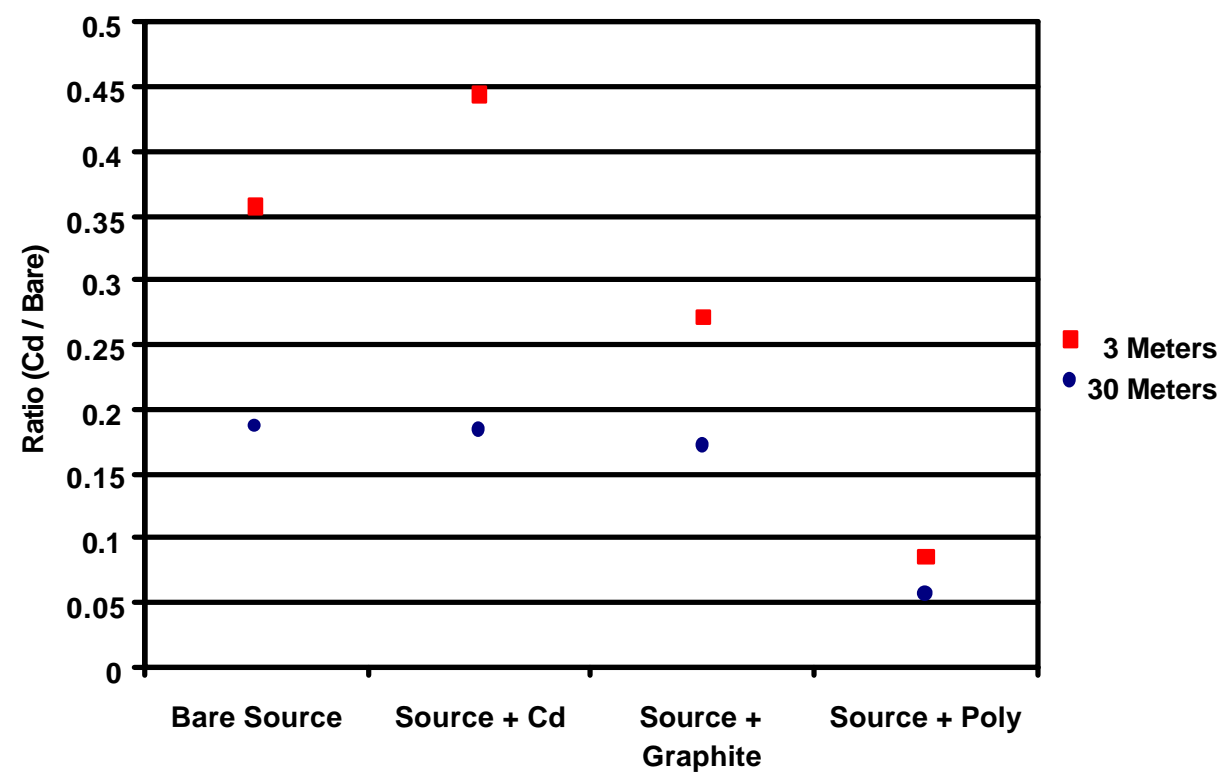

Figure 3.7. Ratio of Counts Obtained in $2.54 \times 35.6 \mathrm{~cm}{ }^{3} \mathrm{He}$ Detector when it is Covered by a Cadmium Sleeve, Compared to Counts for the Bare Detector. Ratio indicates epithermal neutron fraction of the spectrum for various source and detector configurations at distances of 3 and $30 \mathrm{~m}$.

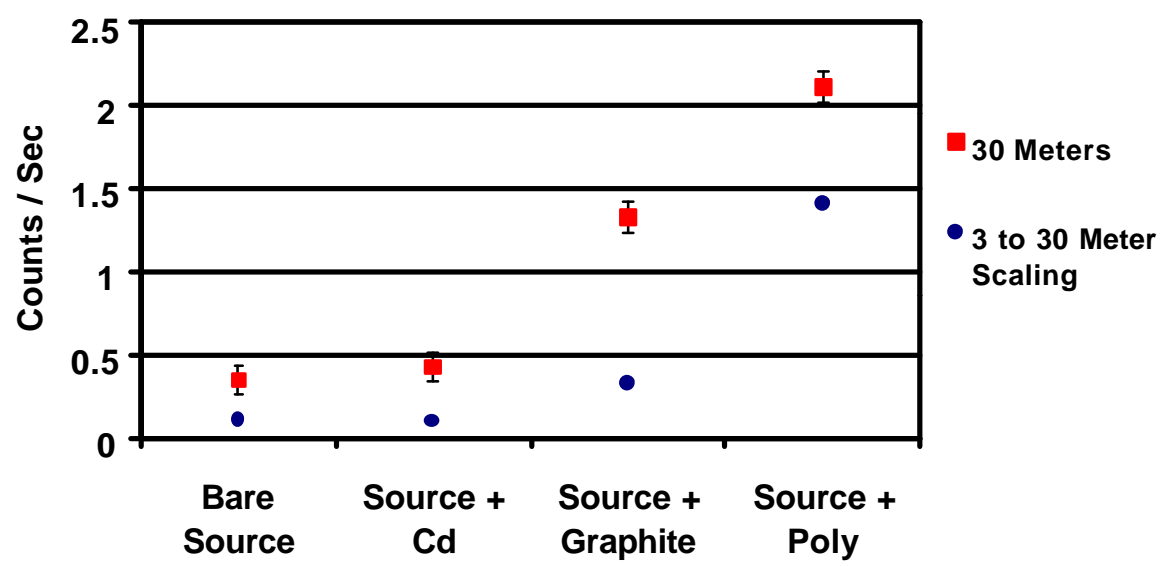

Figure 3.8. Background-Subtracted Count Rates Obtained with Long-Range Detector for Various Source and Detector Configurations (same configurations as in Figure 3.7) 


\subsection{Field Tests for Potential Applications}

Selected field demonstrations are useful in testing applications for the long-range neutron detector. These demonstrations included detecting a neutron source in a moving vehicle and using the detector to monitor the neutron radiation in a source storage room. Other demonstrations included monitoring the neutron emission from a simulated transuranic source and detecting a strong neutron source inside a building with the detector located outside at a distance of $100 \mathrm{~m}$.

\subsection{Detection of Moving Source}

For this demonstration, a moderated ${ }^{252} \mathrm{Cf}$ source $\left(3.36 \times 10^{5} \mathrm{n} / \mathrm{s}\right)$ was located inside a truck (Figure 4.1). The long-range neutron detector was located off to one side of the road at a distance of $10 \mathrm{~m}$, and the count rate was recorded every second as the truck passed by at speeds ranging from 5 to 35 miles per hour. (Speeds were limited to $35 \mathrm{mph}$ for safety at the test location.) Figure 4.2 shows a composite plot of the data obtained for the various truck speeds. Clearly the best signal was obtained when the truck moved slowly, but even at $35 \mathrm{mph}$, the neutron source was detected with a count rate well above background. At $35 \mathrm{mph}$, the counts in the peak totaled 25 counts in the 3 seconds that the count rate exceeded the local background rate of $1.1 \mathrm{c} / \mathrm{s}$. Hence the signal was about $22 \pm 5 \mathrm{c} / \mathrm{s}$. Extrapolation of the results to faster truck speeds suggests that the source should be detectable up to about $55 \mathrm{mph}$. Tests were also conducted with the detector located farther from the road. At a distance of $21 \mathrm{~m}$, the source in the truck could be detected up to a speed of $15 \mathrm{mph}$. This demonstration illustrates a potential application for using the long-range thermal-neutron detector to monitor vehicles for hidden neutron sources.

An alternative mode of operation would be to place the detector in a vehicle and use it to measure neutrons emitted from stationary objects, such as buildings. Neutron sources are more difficult to shield than are gamma-ray sources. Consequently, it may be easier to detect neutron radiation using a remote detector than it would be to detect gamma rays. Attempts to "shield" a neutron source with moderating material may actually increase the thermal neutron flux available for detection by the long-range thermal-neutron detector. 


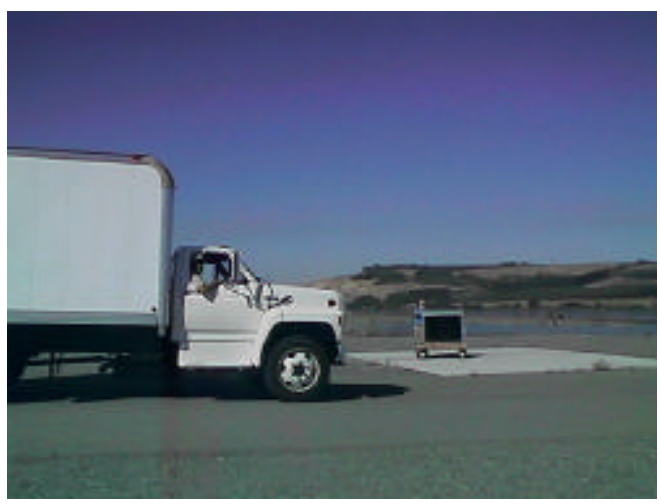

Figure 4.1. Long-Range Detector Used to Detect Neutrons Emitted from a Source in a Truck

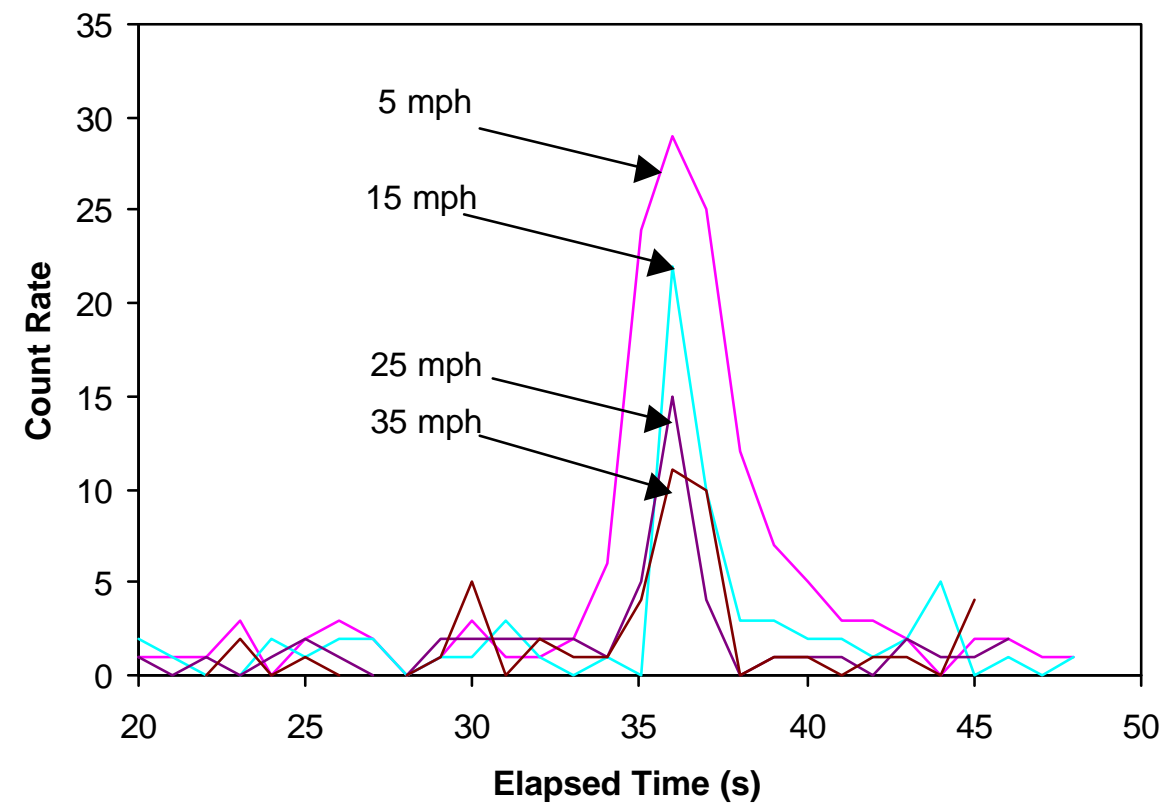

Figure 4.2. Count Rates Obtained as Truck Containing Moderated ${ }^{252}$ Cf Source Drives Past Detector Located $10 \mathrm{~m}$ from Road 


\subsection{Neutron Source Storage Vault Monitoring}

For this test, our neutron detector was placed in one of the storage rooms (Building 326) where neutron and gamma-ray sources are stored. Figure 4.3 shows the detector in the vault with neutron sources located in storage containers. At the time of the test, only a few weak neutron sources were present in the vault, producing a neutron exposure rate of $<1 \mathrm{mR} / \mathrm{hr}$. Figure 4.4 shows the change in measured neutron count rate when one, two, and three people stood between the neutron sources and the detector. The human bodies reduced the thermal neutron flux reaching the detector in these measurements. Additional tests with a single person walking (rather than standing) between the source and detector showed inadequate count-rate changes to positively identify the presence of an individual under the test conditions with a low-neutron ambient flux. The presence of a person may be detectable in a stronger radiation field with shorter measurement intervals than the 1-second ones used.

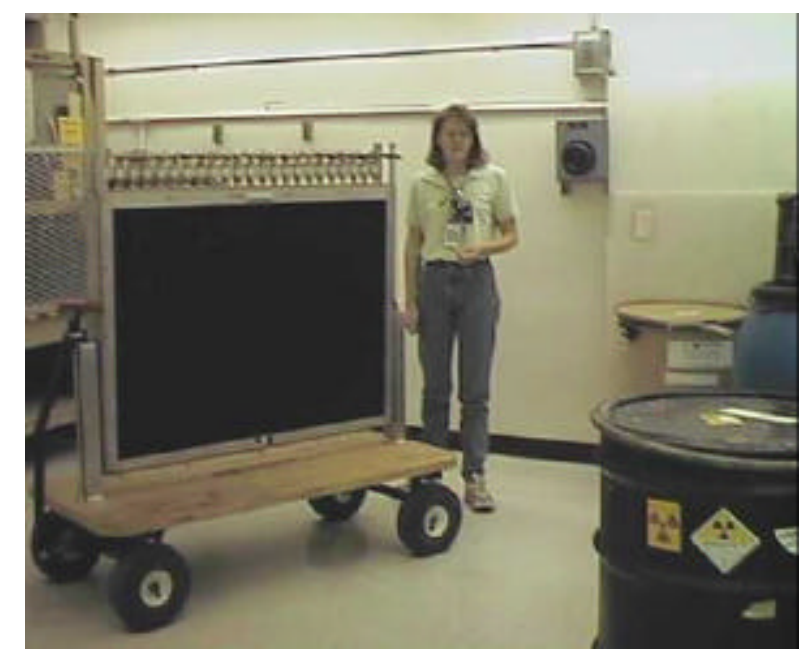

Figure 4.3. Long-Range Detector in Vault Where Radioactive Sources are Stored. Detector monitors thermal neutron flux and any changes resulting from source reconfiguration or human entry.

An alternative use of the detector for source storage monitoring is to mount the collimated detector in the entrance door to the vault. Opening the door changes the direction of the focused measurement with the potential for large changes in count rate. Figure 4.5 shows the count rates obtained in demonstrating this application. In this case, the detector was located at the door, aimed into the storage vault, and then rotated $90^{\circ}$ to simulate opening the door. The large change in count rates (from about 90 to $30 \mathrm{c} / \mathrm{s}$ ) is clearly evident. Using the detector in this mode provides evidence that the door is opened, as well as long-term monitoring of the sources when the door is closed. Changes in the neutron radiation as the result of adding or removing sources should be detectable with these long-term data acquisitions. 


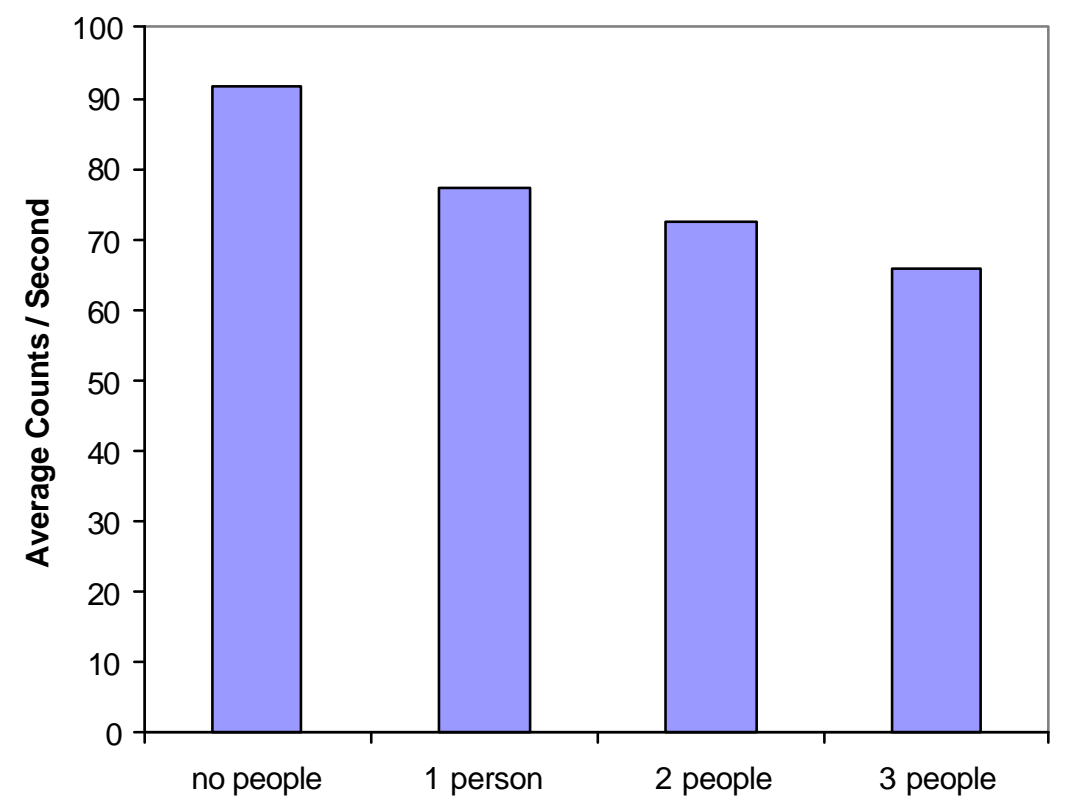

Figure 4.4. Changes in Observed Count Rate when Various Numbers of People are Located Between the Neutron Sources in a Storage Vault and the Detector

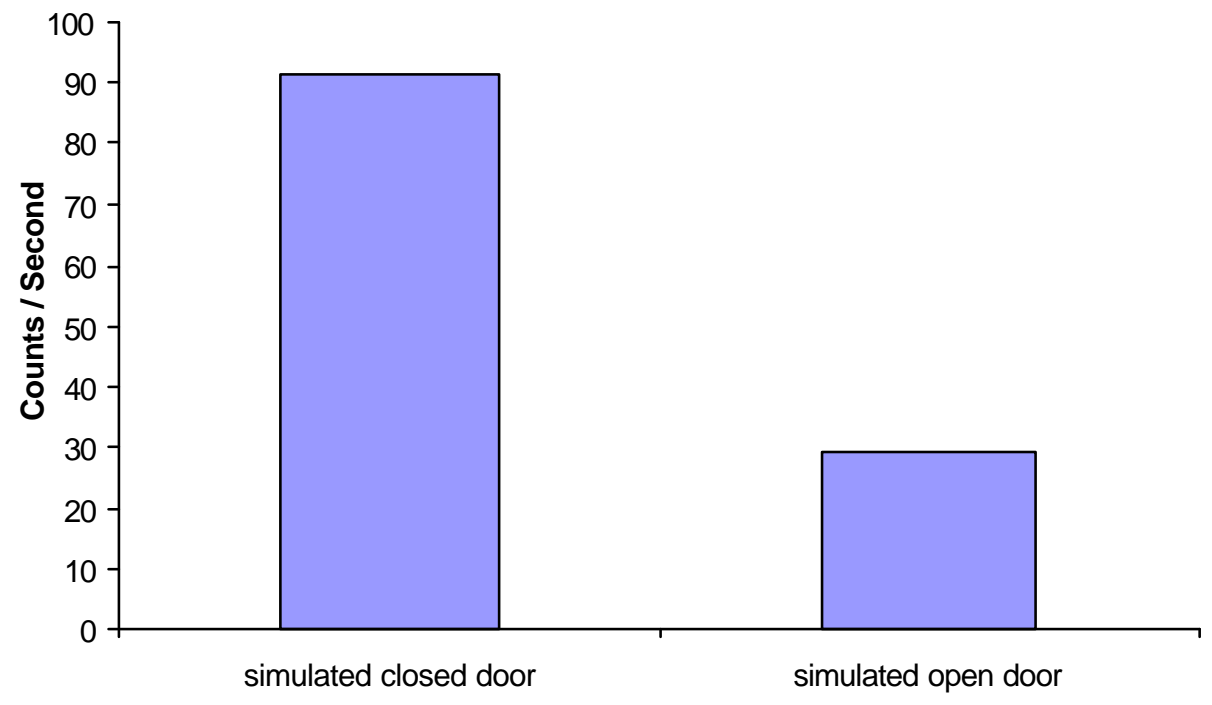

Figure 4.5. Count Rates Observed by Detector Looking into Storage Vault and then Rotated $90^{\circ}$ to Simulate Movement of the Detector if it Were Mounted on a Door that Swings Through $90^{\circ}$ 


\subsection{Transuranic Content of Radioactive Waste}

The long-range neutron detector can be used to measure the neutron emission from containers of radioactive waste. By separating the detector from the source by a distance of several meters, high gamma-ray flux from the source that could interfere with the neutron measurement was reduced. Adding a moderator/reflector around the back and sides of the source served to boost the thermal neutron flux reaching the detector. This concept was tested in a separate project, and details of the results are presented elsewhere (Stromswold et al. 1998). For those tests, ${ }^{252} \mathrm{Cf}$ source was used in combination with a moderator/reflector made of graphite. Figure 4.6 shows one configuration of a graphite cave (external dimensions $0.8 \times 0.8 \times 0.9 \mathrm{~m}$ ) that surrounds the source, with the opening of the cave directed toward the detector located $4.3 \mathrm{~m}$ away. The graphite cave boosted the neutron count rate at the detector by approximately a factor of 10 over what it was without the graphite.

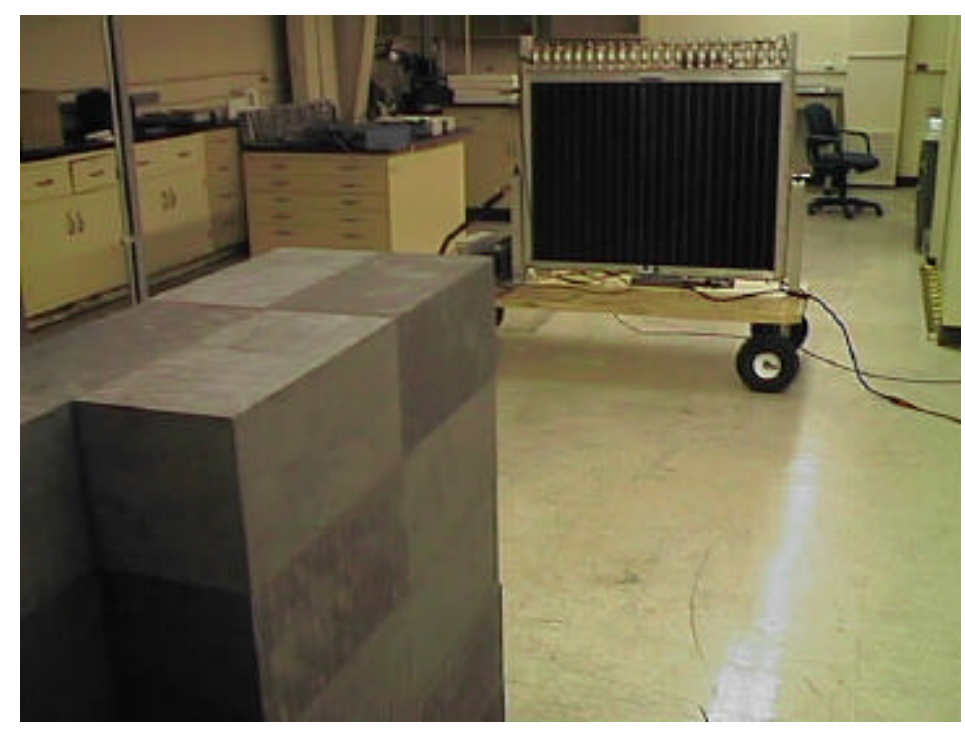

Figure 4.6. Graphite "Cave" (foreground) Used to Moderate Neutrons and Reflect them Toward the Detector Located Several Meters Away

The present long-range neutron detector was not designed to be optimized for use in high gamma-ray fields. The present ${ }^{3} \mathrm{He}$ detectors are limited to a gamma-ray exposure rate of 0.2 to $0.5 \mathrm{R} / \mathrm{h}$ before the neutron count rate is affected by the intense gamma rays. Changing from ${ }^{3} \mathrm{He}$ to $\mathrm{BF}_{3}$ detectors should increase the maximum gamma-ray exposure rate without interference to about $5 \mathrm{R} / \mathrm{h}$. Additional changes, such as using smaller detector tubes and incorporating electronics designed to reject gamma-ray pulses, can increase the maximum gamma-ray operation to about $1000 \mathrm{R} / \mathrm{h}$ at the detector location (Menlove and Beddingfield 1995). In addition, narrower collimation would help to focus the detector's response on the waste container and reduce the background. 


\subsection{Test at $100 \mathrm{~m}$ from $10^{8} \mathrm{n} / \mathrm{s}$ Source}

Figure 4.7 shows the count rates obtained while monitoring the extraction of a ${ }^{252} \mathrm{Cf}$ source emitting $1.2 \times 10^{8} \mathrm{n} / \mathrm{s}$ from a neutron multiplier facility at Hanford. The source was inside a building, and the detector was located outside at a distance of $100 \mathrm{~m}$. The walls of the building appear to be mainly metal, although some moderating material may be present in them. The source was readily detected at this distance, and changes in the count rate were observed as the source was moved within the building. The count rate shown in the figure decreased to background level at $800 \mathrm{~s}$ when the source was temporarily placed below water that was used as a shield for the neutrons. At a distance of $100 \mathrm{~m}$, fast neutrons that are scattered and thermalized en route to the detector reduce the angular sensitivity. Rotating the detector $180^{\circ}$ showed only a slight reduction in the signal, with the $0^{\circ}$ to $180^{\circ}$ count-rate ratio being about 1.3 .

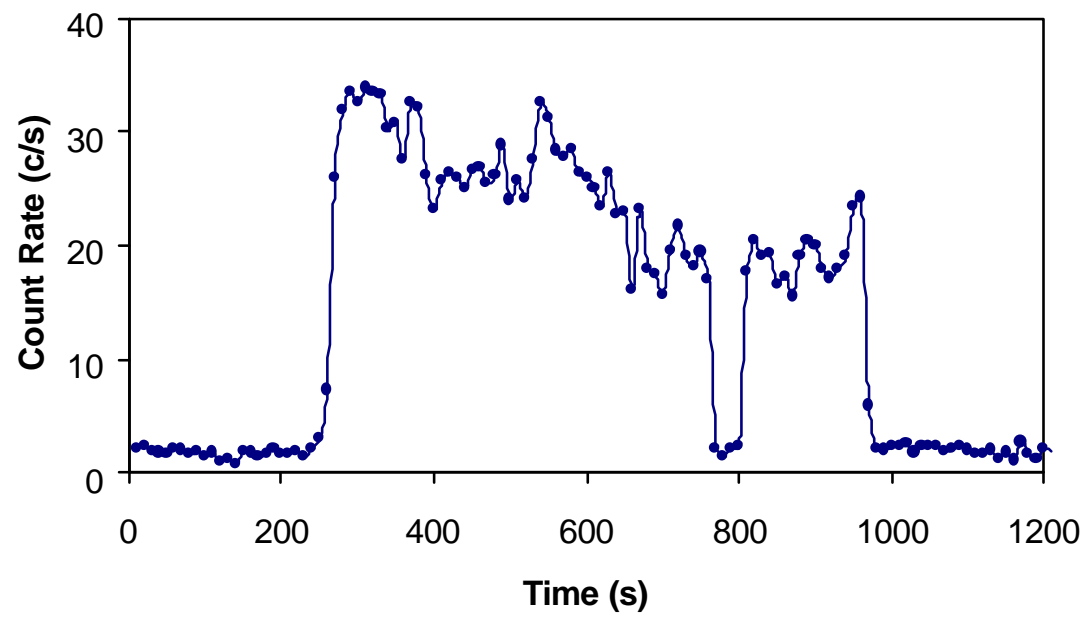

Figure 4.7. Count Rate Obtained at a Distance of $100 \mathrm{~m}$ from a $10^{8} \mathrm{n} / \mathrm{s}$ Source Being Moved Inside a Building 


\subsection{Conclusion}

The long-range neutron detector measures thermal neutrons incident on the detector rather than incorporating polyethylene in the detector to moderate fast neutrons. The absence of polyethylene moderator in the detector aids in reducing background, improves angular sensitivity, and decreases the weight of the detector. The detector has sensitivity to sources of fast neutrons as the result of neutron scattering and moderation in the environment before the neutrons reach the detector. The angular sensitivity to fast-neutron sources is reduced from that for thermal neutrons because of the long travel distances and large scattering angles that can occur.

Tests of the detector quantified the response of the detector to sources at various distances, angles, and neutron energies (degree of moderation). These tests were conducted outside to minimize extraneous scattering of the neutrons. The large surface area $\left(1 \mathrm{~m}^{2}\right)$ of the long-range detector makes it suitable for detecting moderated neutron sources emitting $\sim 3 \times 10^{5} \mathrm{n} / \mathrm{s}$ at distances over $50 \mathrm{~m}$ in counting times of $1000 \mathrm{~s}$. The collimator and ${ }^{10} \mathrm{~B}$ shielding on the detector enhanced the directional response to thermal neutrons while reducing the background counts. The collimator has an acceptance angle of about $45^{\circ}$, as confirmed by measurements using a moderated neutron source located $3 \mathrm{~m}$ away from the detector. At larger separation distances, the angular response broadened as a result of neutron scattering in the air and ground.

Possible applications for the long-range detector include remotely identifying the location of neutron sources, detecting neutron sources in moving vehicles, monitoring source storage vaults, and measuring the transuranic content of radioactive waste. These applications take advantage of the high sensitivity of the detector to thermal neutrons with its reduced background, made possible by the collimator and ${ }^{10} \mathrm{~B}$ shielding. For some applications, the relatively light weight of the detector, made possible because it contains no polyethylene moderator, aids deployment of the detector to remote sites. 


\subsection{References}

Menlove HO and DH Beddingfield. 1995. "The Development of ${ }^{3} \mathrm{He}$ Neutron Detectors for Applications in High Level Gamma-Ray Backgrounds," Lockheed Martin Idaho Technologies Company, In: Proc. $4^{\text {th }}$ Nondestructive Assay Waste Characterization Conference, Salt Lake City, 255-263.

Peurrung AJ, RR Hansen, CL Kunz, DC Stromswold, and PL Reeder. 1998. Long Range Neutron Detection: A Progress Report, PNNL-11995, Pacific Northwest National Laboratory, Richland, Washington.

Peurrung AJ, PL Reeder, EA Lepel, and DC Stromswold. 1997. Location of Neutron Sources Using Moderator-Free Directional Thermal Neutron Detectors, IEEE Transactions on Nuclear Science, Vol 44, 543-550.

Stromswold DC, CL Kunz, AJ Peurrung, and PL Reeder. 1998. "Remote-Handled TRU Characterization Using a Directional Neutron Detector," Lockheed Martin Idaho Technologies Company, In: Proc. $6^{\text {th }}$ Nondestructive Assay Waste Characterization Conference, Salt Lake City, 633-644.

Vanier PE, L Foreman, and EC Seslcow. 1995. "A Thermal Neutron Imager Using Coded Aperatures," Nuclear Materials Management, In: Proc. $36^{\text {th }}$ Annual Meeting INMM, Palm Desert, 24: 842 . 
PNNL-13044

\section{Distribution}

No. of

Copies

OFFSITE

2 DOE Office of Scientific and Technical Communications

Michael O'Connell, NN-20

U.S. Department of Energy

1000 Independence Ave. SW

Washington, DC 20585-0420

David Spears (2), NN-20

U.S. Department of Energy

1000 Independence Ave. SW

Washington, DC 20585-0420

Tracy Wilson, NN-20

U.S. Department of Energy

1000 Independence Ave. SW

Washington, DC 20585-0420
No. of

Copies

ONSITE

55 Pacific Northwest National Laboratory

M. Bliss

P8-20

R. A. Craig

K5-25

G. B. Dudder (10)

B. D. Geelhood

K6-48

A.J. Peurrung (15)

P8-08

P. L. Reeder (5)

P8-08

P8-08

D. E. Robertson

P8-20

D. C. Stromswold (15)

P8-08

R. A. Warner

K6-48

Distr. 1 